\title{
SINGLE PHASE INVERTER USING PWM TECHNIQUE
}

\author{
Prajakta S. Kasulakar \\ Asst. professor, Department of Electrical Engg. \\ Ballarpur Institute of Technology, Ballarpur, India \\ Paras G. Patil \\ Student, Department of Electrical Engg. \\ Ballarpur Institute of Technology, Ballarpur, India
}

\author{
Chetan B. Dethe \\ Student, Department of Electrical Engg. \\ Ballarpur Institute of Technology, Ballarpur, India \\ Pratik N. Murkute \\ Student, Department of Electrical Engg. \\ Ballarpur Institute of Technology, Ballarpur, India
}

\begin{abstract}
An inverter is device that changes the dc voltage into ac voltage thus inverter plays an important role in modern electrical system performers of inverter is necessary for use of electrical energy for various households and industrial purpose. Thus, we are introducing a singlephase inverter using PWM. the use of PWM make it more effective and superior then conventional inverter. This project is basically designed to convert dc source voltage to ac voltage from a battery by using inverter circuit design and construct of $50 \mathrm{~Hz}, 240 \mathrm{~V}, 1 \mathrm{KVA}$ is made for the optimum performance many sub circuits are interconnected with each other for overall operation. The interconnected circuit such as PWM circuit, low battery circuit, over load shutdown circuit, charging control/soft charging circuit protection change over circuit /power supply circuit. It also has output circuit MOSFT and transformer section. The project more introducible to user due to use of visual display component like LED. Use of such inverter can easily contribute to known the start of system easily.
\end{abstract}

\section{INTRODUCTION}

A few year ago, basic need of human beings are food, cloth, shelter but now this scenario is change to food, cloth, shelter and also electricity and we are surrounded by greater technologies. Electricity is biggest technological innovations of human beings.

It is most important factor of daily need and no one cannot imagining world without electricity. Now a day's electricity plays a main role in domestic as well as industrial. Electricity is run our appliances and can also in travelling as like as electric train, electrical car and can also be used in medical (For Ex. ECG, X-ray machine etc.)

To generate this electricity from primary energy. But it is not freely available in nature so that we have to produce electricity from other form of energy Like thermal power plant, hydro power plant, solar power plants etc.
But in Solar power is the conversion of energy from sunlight into electricity using photovoltaic and concentrated solar power system. In photovoltaic cell is a device which converters light into electric currents using the photovoltaic effect. The array of photovoltaic produced direct current power which fluctuates with the sun light intensity. For practical used it converts certain desired voltage or alternating currents through the use of inverters.

And other application of Inverter is when the main power source fails, Inverter has provided emergency power to a load like fans, LED bulbs etc.

An inverter is a device that changes $\mathrm{DC}$ voltage into $\mathrm{AC}$ voltage. A Direct current (DC) is a current that flows in only one direction, while an Alternating current (AC) is that which flows in positive and negative directions.

The electric inverters are a high-power electronics oscillator is namely as mechanical AC to DC converters are works in reverse thus was invented DC to AC. The performance of inverter is opposite to the rectifier.

\section{LITERATURE REVIEW}

In $19^{\text {th }}$ century, DC to AC power converted using Rotary Converters or Motor - generator sets (M-G sets) was reliable at the time was only the converter that converts DC power to AC power. The output waveform fit at the various wide variety of application but it is inefficient.

In $20^{\text {th }}$ Century Vacuum tubes and gas filled tubes are to be used as switch in inverter. Generally, thyratron tube is used as switch.

Since early transistors were not available with sufficient voltage and current ratings for most inverter applications. 1957 introduction of the thyristor or silicon-controlled rectifier (SCR).

Power MOSFET is voltage and not current- controlled. It has a positive temperature coefficient, stopping thermal runaway. 


\section{International Journal of Engineering Applied Sciences and Technology, 2020 \\ Vol. 4, Issue 10, ISSN No. 2455-2143, Pages 225-230 \\ Published Online February 2020 in IJEAST (http://www.ijeast.com)}

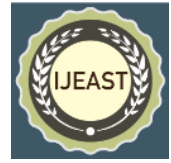

The on - state - resistance has no theoretical limit. Hence on state losses can be far lower. The MOSFET also has a bodydrain diode, which is particularly useful in dealing with limited freewheeling current.

\section{MAJOR COMPONENT}

\section{A. Transformer-}

It is a Passive electric device that transfer electric energy from one circuit to other circuit which are mutual magnetically coupling. A varying current in any coil of transformer produces a varying magnetic flux, which turns induced a varying magnetic electromotive force and wound around same core.

Mostly the transformer is used to step up or step-down voltage or current. The No. of turn on primary winding is a usually different from secondary. Due to both winding is same no of turns, it is isolation transformer provides secondary voltage and current that is same as that of primary. This transformer preventing from transfer of unwanted electrical noise from primary to secondary noise.

The winding of this conventional transformer is wounded on tabular bobbin is made up of plastic and other insulating material the iron or steel core is enclosed the wounded bobbins. the shape of this core generally "E" and "I" the shaped laminated metal sheet, assemble through and round and the wound through bobbins

The generated emf of transformer is given by

$\mathrm{Emf}=4.44 * \mathrm{~F} * \mathrm{Bm} * \mathrm{~A} * \mathrm{~T}_{\mathrm{P}}$

Where, $f=$ frequency of ac input $(50 \mathrm{~Hz})$

$\mathrm{Bm}=$ maximum flux density which is assume to be $1500 \mathrm{wb} / \mathrm{m}$

$\mathrm{T}_{\mathrm{P}}=$ stacking factor $(0.9)$

$\mathrm{A}=$ area of core

No of turns per volt, $\mathrm{N}_{\mathrm{T}}$. $\mathrm{V}^{-1}=7 / \mathrm{A}$

Transformer specification:

Rating of transformer $(\mathrm{KVA})=1 \mathrm{kVA}, \mathrm{E}_{2}=12$ volt

Efficiency of transformer $=85 \%$

Therefore,

input rating $=$ output $/$ efficiency $=1000 \mathrm{VA} / 0.85=1176 \mathrm{VA}$

$\mathrm{V}_{\mathrm{p}}=260$

$\mathrm{I}_{\mathrm{p}}=1176 / 260=4.5 \mathrm{~A} / \mathrm{I}_{\mathrm{S}}=1000 / 12=83 \mathrm{~A}$

\section{B. Power MOSFET (IRFz44)-}

Metal oxide semiconductor field effect transistor (MOSFET). It is three terminal device which can be used as an amplifier or as switch generally, the MOSFET are classified as enhancement and depletion type

FEATURE OF IRFz44:

- Lower input capacitors typically $(1770 \mathrm{pF})$

- Improved gate charge

- Extended safe operating area

- $175^{\circ} \mathrm{C}$ operating temperature

- Lower leakage current $=10 \mu \mathrm{A}(\max$. $)$ at $\mathrm{V}_{\mathrm{ds}}=60 \mathrm{~V}$

- LOWER $\mathrm{R}_{\mathrm{ds}(\mathrm{ON})}: 0.020 \Omega(\mathrm{Tp})$

C. IC SG3524 PWM (50Hz) frequency oscillatorFeatures:

- Complete PWM power control circuitry

- Single ended or push- pull output

- Line and load regulation of $0.2 \%$

- $1 \%$ max temperature variation

- Total supply current is less than $10 \mathrm{~mA}$

- Operation beyond $100 \mathrm{kHz}$

\section{SG3524 description:}

This monolithic integrated circuit contains all the control circuitry for a regulating power supply inverter or switching regulator. Included in a 16-pin dual-in-line package is the voltage reference, error amplifier, oscillator, pulse-width modulator, pulse steering flip-flop, dual alternating output switches and current-limiting and shut-down circuitry. This device can be used for switching regulators of either polarity, transformer-coupled DC-to-DC converters, transformer less voltage doubles and polarity converters, as well as other power control applications. The SG3524 is designed for commercial applications of $0^{\circ} \mathrm{C}$ to $+70^{\circ} \mathrm{C}$.

\section{Battery -}

There are two types of the lead acid batteries (i.e. flat plate batteries and tubular batteries) out of these tubular batteries are best four power backup. Dry type batteries are never use for inverters

These types of batteries are used for all types of inverters including solar inverters

Advantages of tubular batteries over flat plate batteries are It requires minimum maintenance

Due to the internal structure of battery, it needs to topped up with distilled water at longer intervals

It is also safer than the dry battery i.e. the structure of a battery is designed in such a way that there is a no problem of leakage

This type of battery should not trigger any toxic gas release. Hence it can be used inside the house without any tension.

It has a longer lifespan than flat plater battery (about 5 years) 


\section{International Journal of Engineering Applied Sciences and Technology, 2020 \\ Vol. 4, Issue 10, ISSN No. 2455-2143, Pages 225-230 \\ Published Online February 2020 in IJEAST (http://www.ijeast.com)}

It has high efficiency and are associated with low current wastage.

\section{Batteries specification:}

Battery voltage: $12 \mathrm{~V}$

Capacity: $\quad 26 \mathrm{Ah}$

Type: $\quad$ Sealed lead acid battery

Length: $\quad 6.58$ "

Width: $\quad 6.89^{\prime \prime}$

Height: 5.04"

Rechargeable: yes

Recyclable: yes

Memory effect: no

Operating temperature range:

At the time of discharging: $\quad-40^{\circ} \mathrm{C}$ to $+60^{\circ} \mathrm{C}$

At the time of charging: $\quad-20^{\circ} \mathrm{C}$ to $+50^{\circ} \mathrm{C}$

\section{E. Resistance-}

$220 \Omega / 5 \mathrm{~W}, 0.01 \Omega / 2 \mathrm{~W}, 47 \Omega / 2 \mathrm{~W}, 220 \mathrm{~K} \Omega / 2 \mathrm{~W}$

\section{F. Capacitor-}

$100 \mu \mathrm{F} / 50 \mathrm{~V}, 1000 \mu \mathrm{F} / 63 \mathrm{~V}, 330 \mu \mathrm{F} / 35 \mathrm{~V}, 2.2 \mu \mathrm{F} / 50 \mathrm{~V}, 4.7$ $\mu \mathrm{F} / 63 \mathrm{~V}, 10 \mu \mathrm{F} / 50 \mathrm{~V}, 22 \mu \mathrm{F} / 50 \mathrm{~V}, 0.47 \mu \mathrm{F} / 50 \mathrm{~V}, 0.1 \mu \mathrm{F} / 10 \mathrm{~V}$ (Ceramic)

\section{WORKING OPERATION}

The working operation of inverter is divided into following section

\section{A. Output Section-}

the no. of terminals of all MOSFET is three (ie. DRAIN, source $\&$ gate) out of this drain (D) of all MOSFET of one channel connected together and one end of the inverter bifilar winding is connected to this connection. The same is done to the second channel and other end of inverter winding. Center tapping of bifilar winding is connected to the positive terminal of battery and the negative terminal of battery is connected to the source terminal of each MOSFET. Because, current flows through the first and second half of the transformer's bifilar winding alternatively. This will cause alternating current flowing will induce an AC current of $50 \mathrm{~Hz}$ in $260 \mathrm{~V}$ tapping's of transformer. This tapping is connected to the N/O-2 terminals of relay. If the AC mains is failed, pole P-2 of the relay is connected to the N/O-2 terminals and thus an AC voltage is produced by the inverter reaches the output socket.

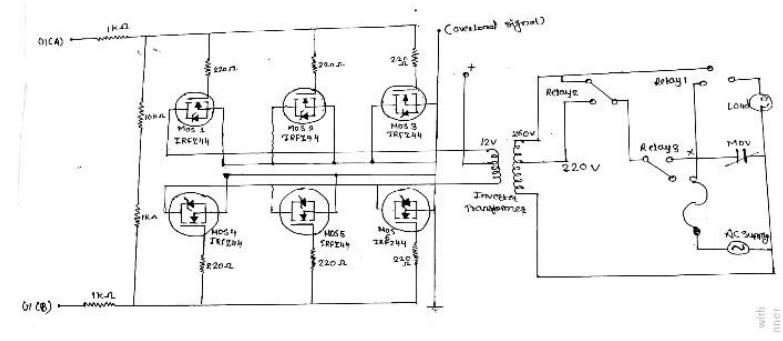

Fig. (a) output section

\section{B. PWM Section-}

To obtain the steady output voltage of $230 \mathrm{~V}$ or $110 \mathrm{~V}$ pulse with modulation technology used in inverter based on PWM are more superior to the conventional inverter PWM method is used to detract over all harmonic distortion in the load current. PWM is realized by feeding back by AC supply generated by the inverter to the PWM IC1 to keep the pulse with output from pin 11 and 14 constant. A bridge rectifier is made up of 4 diode (D2, $\mathrm{D} 3$, D4, and D5) is connected to the drain terminal of the MOSFET for providing the feedback to the PWM controller IC the output of the bridge rectifier is filtered by a $10 \mu \mathrm{F}$ capacitor and gives to the pin 1 of PWM IC through adjusting preset (potential circuit) 10K and PWM adjustment VR2.

The pin diagram of PWM IC 1 is shown in fig (b). The pin $1,2 \& 9$ are three pins of an internal Op-Amp, pin 1 and pin 2 are input pins and pin 9 is the output pin. Pin 1 is given feedback signal, pin 2 is given regulated power supply as a reference voltage through voltage divider circuit of two $10 \mathrm{~K}$ resistor. Pin 16 of PWM IC 1 is taken the reference voltage. Pin 9 is internally connected to the section that control the width of signal (oscillating frequency). by varying the signal at pin 9 will result in a change in width of the output frequency and this will maintain the steady state output of inverter $(220 \mathrm{~V})$.

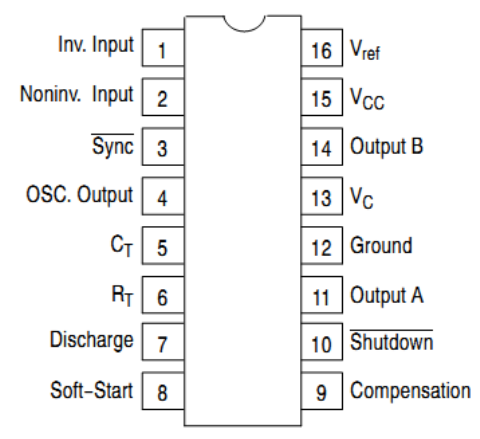

Fig. (b) Pin diagram of SG3524

\section{Protection Section for Low Battery-}

In previous the LM3914 IC is used. Which is also a good IC to make a quality battery monitor but its cost is higher than LM324. 


\section{International Journal of Engineering Applied Sciences and Technology, 2020 \\ Vol. 4, Issue 10, ISSN No. 2455-2143, Pages 225-230 \\ Published Online February 2020 in IJEAST (http://www.ijeast.com)}

Pin Description: In low battery condition, an Op-Amp made of pin 4,5,2 of IC 2 (LM324), T5, SCR Q1 and low battery indicator LED is used. Pin 4 of IC 2 is given a constant reference voltage of $5 \mathrm{~V}$ (from IC 1's pin 16) through $47 \mathrm{~K}$. pin 5 is given positive supply from the battery through $47 \mathrm{k}, 10 \mathrm{k}$, $10 \mu \mathrm{F}$ and $4.7 \mathrm{k}$ preset VR4 network.

Basic working of circuit - For the overload protection, taping is taken from the battery terminal and it is fed to the inverting input of an op-amp ad reference voltage is fed to the noninverting input of an op-amp which is adjusted by preset pot to your convenience. If the output of an op-amp is below (greater than zero) the required voltage then the circuit will be turn $\mathrm{ON}$ and which is fed to the NPN transistor (BC547). When NPN transistor is ON then it causes for the operation buzzer and Switch ON the overload indicator.

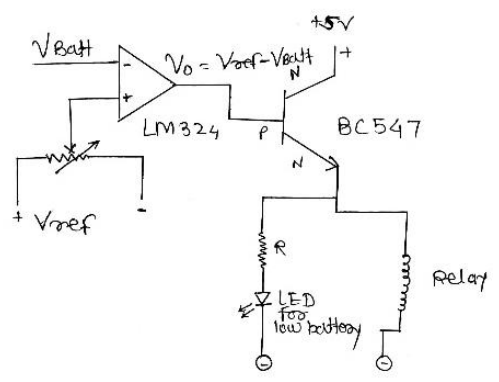

Fig. (c) Basic working of circuit of low battery circuit

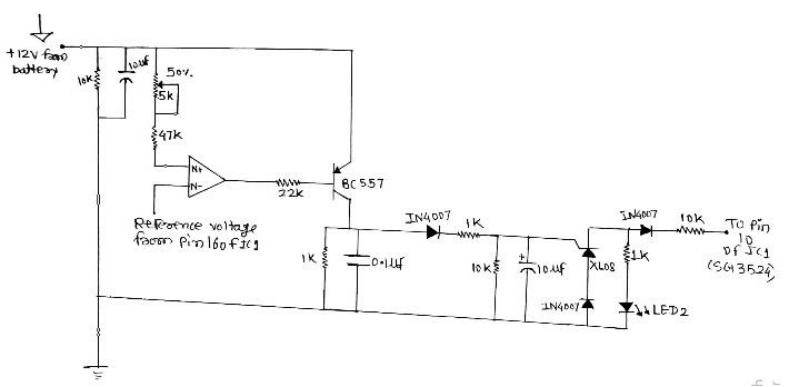

Fig. (d) low battery circuit

\section{Protection section for overload battery-}

Pin description: It consist of two Op-Amp A and C made of pin $6,7,1$ and pin 10, 11, 13 of IC (LM324). It also uses two transistor T3 and T4. Pin 6,7and pin 10,11 are the input pins for $\mathrm{A}$ and $\mathrm{C}$ their outputs are pin 1 and 13.

Basic working of circuit - For the overload protection, the current is converted in to the voltage i.e. current is passes through the $0.1 \Omega$ and voltage drop the produces and it is fed to the inverting input of an op-amp ad reference voltage is fed to the non- inverting input of an op-amp which is adjusted by preset pot to your convenience. If the output of an op-amp is below (less than zero) the required voltage then the circuit will be turn ON and which is fed to the PNP transistor (BC557). When PNP transistor is ON then it causes for the operation relay and Switch ON the overload indicator and shutdown the inverter to prevent the Overloading battery.

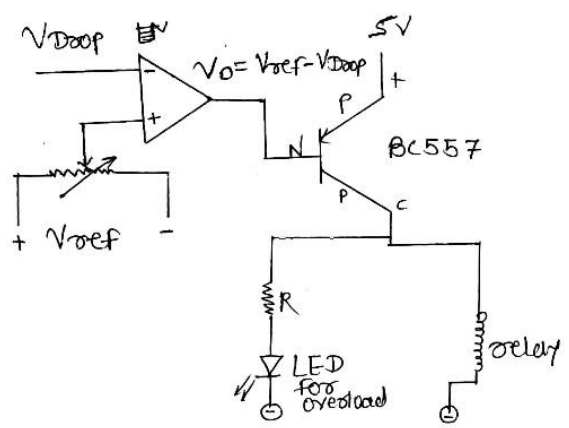

Fig. (e) Basic working of circuit of overload battery circuit

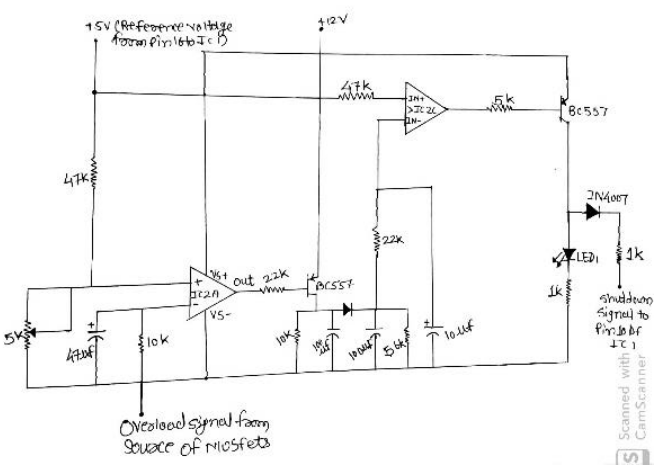

Fig. (f) Overload battery circuit

\section{$E$. Battery charging section-}

In this mode inverter works as a rectifier i.e. inverter transformer is work as a step-down transformer As the inverter is work as a rectifier during charging mode (due to internal diode) the drain being cathode and source as anode. positive terminal of the battery is connected to the center taping of transformer and negative MOSFET source when the inverter receives the ac main supply, inverter transformer and MOSFET together work as a charger and it will charge the battery it also provides protection from over charging of battery.

\section{ADVANTAGES}

1. It improves switching speed

2. It improves dynamic performance that requires even less power from the driver

3. It had a highest frequency application and long duty cycle

4. It has low voltage application

5. Due to the multilevel inverter the output wave form just closer to sinusoidal hence it will reduce stresses on the insulation level of motor (as a load). 


\section{International Journal of Engineering Applied Sciences and Technology, 2020 \\ Vol. 4, Issue 10, ISSN No. 2455-2143, Pages 225-230 \\ Published Online February 2020 in IJEAST (http://www.ijeast.com)}

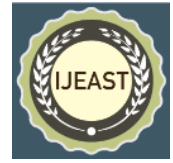

6. It can be energy efficient way of charging.

\section{DISADVANTAGES}

1. It required rectification and smoothing on the output if output is to be DC.

2. It may produce radio interference or audio able tones.

3. It may produce $\mathrm{AC}$ at non specified frequency.

4. In certain type of UPS inverter may need to face synchronized to the AC input power to ensure a spice free switched over.

5. It may produce access output voltage under on load or very lite load condition.

\section{RESULT}

In case of multilevel inverter as the level increases, the output waveform will closer to the sinusoidal waveform as shown below fig.

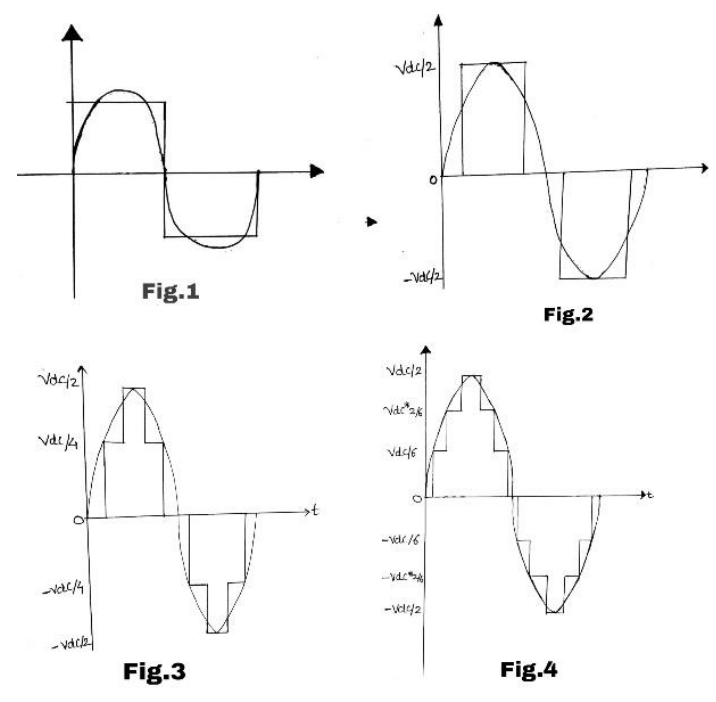

Fig 1. Single level inverter, fig 2. Third level inverter, fig. 3 fifth level inverter, fig. 4 seventh level inverter

\section{ACKNOWLEDGEMENT}

We would like to express our deep and sincere gratitude to our guide prof. Prajakta kasulkar for guiding me to accomplish this project work. It was our privilege and pleasure to work under her able guidance. We are indeed grateful to her for providing helpful suggestion, from time to time. Due to her constant encouragement and inspiration we are able to present this project work. We are very much thankful to prof. V. P pimpalkar, head of electrical engineering department for providing all the necessary facilities to carry out our project work. We are also thankful to Dr. Rajnikant principal Ballarpur Institute of Technology, Ballarpur. for supporting and coordinating the project work as well as guiding and providing necessary facilities in time without delay in things. We Must thank sincerely to all professor and non-teaching of BIT, Ballarpur without whom work not have possible.

\section{CONCLUSION}

For the optimum performance this construction of $1 \mathrm{KVA}$ single phase inverter using PWM is one of the better constructions than another inverter. The use of control circuit makes this inverter as a novel design. The project successfully executed on the basis to prevent it from overload damaged, battery short down. Also, it is built in such way that it increases the life span of battery which is use. One of main advantage is that the status of system can be easily known due to incorporation of monitoring system into the inverter system.

\section{REFERANCE}

[1] Babarinde,O. O., Adeleke, B. S., Adeyeye, A. H., Ogundeji, O. A., and Ganiyu A. L (2014) Design and Construction of $1 \mathrm{kVA}$ Inverter. International Journal of Emerging Engineering Research and Technology. Volume 2, pp 201-212 ISSN: ISSN 2349-4409.

[2] Wikipedia : Power inverter

[3] https://www.electronicproducts.com/Analog_Mixed Signal_ICs/Discrete_Power_Transistors/MOSFET_v S_IGBT.aspx\#

[4] Wensong Yu, jih-Sheng Jason Lai, Hao Qian, Christopher Hutchens, (2011). "High-Efficiency MOSFET Inverter with H6-Type Configuration for Photovoltaic Nonisolated AC-Module Applications". IEEE Transactions on Power Electronics ( Volume: 26 , Issue: 4 , April 2011 )

[5] Juan Colmenares ,Dimosthenis Peftitsis , Jacek Rabkowski ,Diane-Perle Sadik ,Georg Tolstoy (2015) "High-Efficiency 312-kVA Three-Phase Inverter Using Parallel Connection of Silicon Carbide MOSFET Power Modules". IEEE Transactions on Industry Applications ( Volume: 51 , Issue: 6, Nov.Dec. 2015 )

[6] K. Sato, H. Haga and S.K Nagaoka, (2016) SinglePhase 7-Level Inverter For Reducing Number Of Switches, Intelec, Int. Telecommun Energy Conf., Vol 2016.

[7] V Letsoin, F A Samman, A E U Salam, (2018) ThreePhase DC-AC Inverter with Low Power Dissipation Filter For Photovoltaic-Based MicroGrid Scale Electric Power System, The 9th International Conference on Electrical, Electronics, Communications, Controls and Informatics System, Batu City, Indonesia.

[8] N.-C. Yang and M.-D. Le, Optimal design of passive power filters based on multi-objective bat algorithm and pareto front, Applied Soft Computing, vol. 35, pp. 257266, 2015. 


\section{International Journal of Engineering Applied Sciences and Technology, 2020 \\ Vol. 4, Issue 10, ISSN No. 2455-2143, Pages 225-230 \\ Published Online February 2020 in IJEAST (http://www.ijeast.com)}

[9] Xu Jun, Han Kailing,(2016) "The single phase inverter design for photovolataic systems", 2016 International Symposium on Computer, Consumer, and Control, pp 341-344

[10]Didi Istardi, Andy Triwinarko, (2014) “ Design of Snubber Circuit and PI Control to Achieve Load Independent Output Voltage in Micro Smart Home System', International Conference on Smart-Green technology in Electrical nad Information Systems, pp. 7-12, Bali, Nov 2014.

[11] https://www.indiamart.com/proddetail/exide-12v26ah-power-safe-plus-smf-battery-11399137162.html

[12] M. Buyuk, A. Tan, M. Tumay, and K. C. Bayindir, (2016) Topologies, generalized designs, passive and active damping methods of switching ripple filters for voltage source inverter: A comprehensive review, Renewable and Sustainable Energy Reviews, vol. 62, pp. 4669.

[13] N.-C. Yang and M.-D. Le, (2015) Optimal design of passive power filters based on multi-objective bat algorithm and pareto front, Applied Soft Computing, vol. 35 , pp. 257266.

[14] https://www.alldatasheet.com

[15] https://www.quora.com/What-are-the-advantagesand-disadvantages-of-multilevel-inverters

XI. MODEL

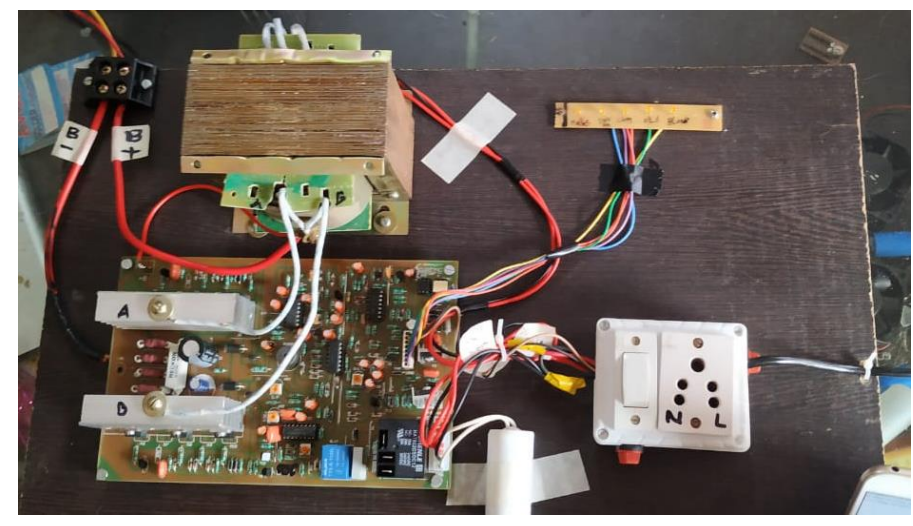

